\title{
The Diagnostic Role of Magnetic Resonance Enterography as a Complementary Test to Colonoscopy in Active Crohn's Disease
}

Arvin Aryan ${ }^{1}$, Zahra Azizi², Azam Teimouri ${ }^{3}$, Nasser Ebrahimi Daryani ${ }^{4 *}$, Najme Aletaha ${ }^{5}$, Ali Jahanbakhsh ${ }^{6}$, Mohammad Kazem Nouritaromlou ${ }^{6}$, Forough Alborzi ${ }^{3}$, Masoud Mami ${ }^{7}$, Vahid Basirat ${ }^{8}$,Sanam Javid Anbardan ${ }^{2}$

1. Assistant Professor of Radiology, Imam Khomeini Hospital, Tehran University of Medical Science, Tehran, Iran

2. Researcher, Iran University of Medical Sciences, Tehran, Iran

3. Assistant Professor of Isfahan University of Medical Sciences, Isfahan, Iran

4. Professor of Gastroenterology, Imam Khomeini Hospital, Tehran University of Medical Science, Tehran, Iran

5. Assistant Professor of Gastroenterology, Imam Khomeini Hospital, Tehran University of Medical Science, Tehran, Iran

6. Researcher, Tehran University of Medical Science, Tehran, Iran

7. Fellow of Gastroenterology, Imam Khomeini Hospital, Tehran University of Medical Science, Tehran, Iran

8. Resident of Internal Medicine, Imam Khomeini Hospital, Tehran University of Medical Science, Tehran, Iran

\section{* Corresponding Author:}

Nasser EbrahimiDaryani, MD Floor 2, no.130, ShahidNaseri Street, Valiasr Ave, Tehran, Iran Telefax: + 982188793896 Email: nebrahim@sina.tums.ac.ir Received: 20 Dec. 2015 Accepted: 10 Mar. 2016

\section{ABSTRACT}

\section{BACKGROUND}

According to recent studies comparing magnetic resonance enterography (MRE) with ileocolonoscopy for assessing inflammation of small bowel and colonic segments in adults with active Crohn's disease (CD), we aimed to compare the accuracy of these two diagnostic methods in Iranian population.

\section{METHODS}

During 2013-2014 a follow-up study was done on 30 patients with active CD in a gastroenterology clinic affiliated to Tehran University of Medical Sciences. MRE and ileocolonoscopy were performed for all the patients. All statistical analyses were performed using SPSS (version 18) and $p$-value $<0.05$ was considered as statistically significant.

\section{RESULTS}

Of the 30 patients with active CD, 11(36.7\%) were men and $19(63.3 \%)$ were women with mean age of $37.30 \pm 13.66$ years (range: $19-67$ years). MRE had sensitivity and specificity of $50 \%$ and $90 \%$ with positive predictive value (PPV) and negative predictive value (NPV) of 71.43 and 78.26, respectively for localizing sigmoid lesions and ileum had sensitivity and specificity of 84.21 and 45.45 with PPV and NPV of 72.73 and 62.50, respectively.

\section{CONCLUSION}

While moderate sensitivity and high specificity of MRE in localizing colonic lesions makes it an appropriate confirmatory test after colonoscopy, the reported high sensitivity and moderate specificity of MRE versus colonoscopy in detecting ileal lesions makes it a suitable screening test for ileal lesions. Finally we can conclude that MRE can be an important complementary test to colonoscopy in detecting active disease.

\section{KEYWORDS}

Magnetic Resonance Enterography, Ileocolonoscopy, Active Crohn's disease, Diagnostic accuracy

Please cite this paper as:

Aryan A, Azizi Z, Teimouri A, Ebrahimi Daryani N, Aletaha N, Jahanbakhsh A, Nouritaromlou MK, Alborzi F, Mami M, Basirat V, Javid Anbardan S. The Diagnostic Role of Magnetic Resonance Enterography as a Complementary Test to Colonoscopy in Active Crohn's Disease. Middle East J Dig Dis 2016;8:93-101. DOI : 10.15171/mejdd.2016.13

\section{INTRODUCTION}

Crohn's disease (CD) is a chronic, idiopathic inflammatory bowel disease, which could affect all parts of the gastrointestinal tract predominantly the small bowel where the terminal ileum is the most frequently involved site. 
Both segmental and transmural involvement of the intestine is distinctive of the CD. ${ }^{1-8}$ This chronic process usually initiates in early adulthood with a second peak in the elderly population. While various clinical presentations can be attributed to the CD; diarrhea, abdominal pain, and weight loss are the most common manifestations. ${ }^{1,2}$

The natural history of the disease is quite unpredictable alternating between flares, remissions, and relapses. Meanwhile, approximately two-third of patients develop complications such as fistulas, strictures, abscesses, obstructions, and malignancy, which might require surgical interventions. ${ }^{1,2,9,10}$ Furthermore, CD lesions lead to a variety of anatomical malformations such as bowel wall thickening, strictures, and ulcerative mucosal lesions associated with abdominal fat involvement and per visceral lymph node enlargement caused by diffuse inflammation. ${ }^{11-13}$

Currently; a combination of clinical, endoscopic, radiological, and biochemical investigations are used for diagnosis of CD, among which ileocolonoscopy and taking biopsy samples are the first-line steps. ${ }^{1,3,14}$ Since upper gastrointestinal endoscopy and ileocolonoscopy have limited functionality for evaluating the small bowel as the most commonly affected part of the bowel by CD, small bowel's investigation for guiding succeeding therapeutic strategies has always been a challenge. ${ }^{2,3}$ Initially, radiological evaluations of small bowel in active CD such as enteroclysis and small bowel follow-through mostly relied upon fluoroscopic techniques, which offer limited data about bowel wall involvement and extraluminal extension of the disease. ${ }^{15-17}$ Currently, several cross-sectional imaging modalities such as magnetic resonance (MR) imaging and computed tomography (CT) that provide several advantages over traditional modalities have widely replaced them. ${ }^{18,19}$ Firstly, CT enterography and MR enterography (MRE) allow more comprehensive evaluation of mural disease, bowel wall thickening and extra-luminal complications of Crohn's disease. ${ }^{15,20,21}$ Secondly, the disease activity and severity, commonly assessed by the Crohn's Disease Activity Index (CDAI), can be evaluated by an MRE-based score. ${ }^{1,12}$ Finally, regarding early age of onset in $\mathrm{CD}$, chronic and relapsing nature of the disease, frequent small bowel lesions among symptomatic CD patients, and increasing risk of developing complications ${ }^{22}$, repeated imaging examinations is usually necessary for follow-up of patients with
CD. ${ }^{23,24}$ Thus, in order to avoid exposure to radiation and at the same time to identify active ileitis and investigate extraenteric complications, MRE has been increasingly gain popularity in recent years for evaluating patients with CD during follow-up. ${ }^{2,15,25,26}$ Based on above-mentioned rationales, ECCO (European Crohn's and Colitis Organization) has recommended applying cross-sectional imaging modalities for diagnosis and follow-up of patients with $\mathrm{CD}$ in its latest guidelines. ${ }^{3,14}$ Considering the diagnostic limitations of ileocolonoscopy in evaluating small intestine a location that is commonly involved in $\mathrm{CD}$ in the current study, and its invasiveness, intolerability, and risks of perforation in detecting colonic lesions in patients with repeated follow-up visits, we primarily aimed to prospectively evaluate the sensitivity, specificity, and accuracy of MRE compared with ileocolonoscopy for assessing active Crohn's inflammation in adult patients in Iranian population. ${ }^{27,28}$

\section{MATERIALS AND METHODS}

From 22 December 2013 to 22 December 2014, a follow-up study was done on 30 patients with active CD (CDAI $>150)$ in a gastroenterology clinic affiliated to Tehran University of Medical Sciences. The current single-center study was approved by Institutional Ethics Committee of the University.

Thirty consecutive symptomatic patients consisted of 11 (36.7\%) men and $19(63.3 \%)$ women with mean age of $37.30 \pm 13.66$ (range: 19-67 years) with established diagnosis of CD -based on endoscopic and histological criteria- who required a new bowel assessment to support modifications in therapeutic approach, were enrolled in this study.

The inclusion criteria were confirmed active CD with CDAI $>150$ and age $>18$ years. The exclusion criteria were acute bowel obstruction, elevated serum creatinine, severe claustrophobia, cardiac pacemaker, implanted magnetic foreign bodies, pregnancy, lactation, and acute infection. After obtaining an informed consent, a standardized examination including medical history, physical examination, measuring $\mathrm{C}$-reactive protein (CRP), erythrocyte sedimentation rate (ESR), and fecal calprotectin in association with a clinical assessment of disease activity by Crohn's Disease Activity Index (CDAI) were performed for all the patients. The disease was considered clinically 
active in patients with CDAI scores higher than 150 . Then, all the patients underwent diagnostic evaluations as well as MRE and reference examination (ileocolonoscopy). During the period of diagnostic examinations, no modification was done on pharmacologic treatment which was being used by the patients.

Reference studies: The ileocolonoscopy was performed as the reference investigation for the evaluation of the colon and the terminal ileum (last $20 \mathrm{~cm}$ ) by an experienced endoscopist for all the patients, following the standard protocol. MRE was performed in the same day or within maximum 2 weeks after colonoscopy by an expert who was blind to the results of colonoscopy. The inflammatory lesions at endoscopy were evaluated based on Crohn's Disease Index of Severity (CDEIS ) and the CDEIS higher than 6 was defined as endoscopic activity.

\section{Bowel Preparation for Colonoscopy:}

Patients were advised to consume a clear liquid dietary regimen 24 to 72 hours before colonoscopy according to their bowel habit. A total of 4-8 five-mg bisacodyl tablets (TolidDarou,Tehran, IRAN) were prescribed for the patients every 4 to 6 hours. Furthermore, the patients were prescribed 6-8 boxes of polyethylene glycol (PEG) (each 70 grams solved in 1 liter water) until clearance of rectal output.

\section{MR Enterography Technique:}

MRE was performed with 3-tesla Siemens (3T Magnetom Trio Version syngo B17), in supine position using an eight channel abdominal body coil by a radiologist who was blind to the results of ileocolonoscopy and the patients' history.

MRE examinations were performed after 4-6 hours of fasting. An hour prior to imaging, 3 liters of PEG solution $(75 \mathrm{gr} / \mathrm{L})$ as an oral contrast media was administered to all cases every 5 minutes to achieve the small bowel distention. Adequate luminal distension was determined by a control T2 HASTE (half-fourier acquired single-shot fast spin echo) image in coronal section. If satisfactory luminal distention was achieved then MRE images would be taken. Otherwise if adequate luminal distention was not achieved, control images would be repeated every 5 minutes until achieving acceptable luminal distension, then MRE images were taken.
In order to attenuate the bowel peristalsis and achieve a homogenous bowel distention, $20 \mathrm{mg}$ Hyoscine-Nbutylbromide (Osveh, Tehran, IRAN) was administered intramuscularly to each patient prior to and during MRE. Axial and coronal images of $\mathrm{T} 2 \mathrm{w}$ were taken first and $\mathrm{T} 1$ images were obtained after injection of $15 \mathrm{ml}$ Dotarem (GadoterateMeglumine, importer company coildaroo, originally produced by GUERBET company, FRANCE) containing gadolinium.

The following radiological variables were evaluated during MRE: mucosal enhancement and presence of perienteric vascularization (comb sign), ulcers, mesenteric fat stranding, mural thickening, engorgement of vasa recta, fibro-fatty proliferation, dilated amorphous loops, entero-entric fistula, enlargement of mesenteric lymph nodes, fibro-stenosis, perianal fistula, and abscess.

In order to compare the endoscopic and imaging results, the ileocolonic tract was divided into eight tracts: ileum, ileocecal valve, cecum, ascending colon, transverse colon, descending colon, sigmoid colon, and rectum. Then, a per segment analysis was performed.

\section{Statistical Analysis}

All the statistical analyses were performed using the SPSS software (version 18). Descriptive statistics were performed for colonoscopy and MRE results. A comparison at the level of each different segment was derived between the lesions found at MRE and findings at ileocolonoscopy by cross tab and Chi square test. Sensitivity, specificity, positive likelihood ratio (PLR), negative likelihood ratio (NLR), positive predictive value (PPV), negative predictive value (NPV), and K of MRE in localization of lesions of all the eight segments were determined on a per-segment and overall basis. $\mathrm{P}$ value $<0.05$ was considered as statistically significant. Considering definition, $\mathrm{k}<0,0<\mathrm{k}<0.20,0.21<\mathrm{k}<0.40,0.41<\mathrm{k}<0.60$, and $0.61<\mathrm{k}<0.80$ indicate poor agreement, slight agreement, fair agreement, moderate agreement, and substantial agreement, respectively, while $\mathrm{k}>0.80$ indicates excellent agreement.

\section{RESULTS}

\section{Patients' Characteristics and Clinical Manifestation:}

Total of 30 patients with active Crohn's disease (CADI $>150)$ were included in the study. Of them 11 
Table 1: Clinical Manifestation

\begin{tabular}{lc}
\hline Positive family history & $2(6.7 \%)$ \\
\hline Anemia & $15(50.0 \%)$ \\
\hline Arthropathy & $8(26.7 \%)$ \\
\hline Eye involvement & $4(13.3 \%)$ \\
\hline Skin involvement & $4(13.3 \%)$ \\
\hline Anal fistula & $12(40.0 \%)$ \\
\hline Fever & $9(30.0 \%)$ \\
\hline Colectomy surgery & $1(3.3 \%)$ \\
\hline Enteral surgery & $1(3.3 \%)$ \\
\hline Extra GI manifestation & $20(66.7)$ \\
\hline
\end{tabular}

$(36.7 \%)$ were men and $19(63.3 \%)$ were women with mean age of $37.30 \pm 13.66$ (19-67) years. Mean duration of disease and defecation frequency were $6.46 \pm 8.35$ (138) years and 10.40 \pm 8.77 (2-40) times, respectively. Mean ESR, CRP, and fecal calprotectin level were $57.53 \pm 26.57$ (25-125), 51.36 \pm 22.26 (22-96), and 912.63 \pm 481.65 (991800 ), respectively. Extra gastrointestinal (GI) manifestation was present in $66.7 \%$ (20) of the patients and $40 \%$ (12) had anal fistula. Patients' clinical manifestation is summarized in table 1. Distribution of GI involvement and findings in colonoscopy and MRE are shown in tables 2 and $3 \mathrm{a}$, and $3 \mathrm{~b}$. The most frequent involved segment in colonoscopy and MRE was ileum that was affected in 19 (23.8\% among involved segments and $70.4 \%$ of all cases) and 22 patients (34.4\% among involved segments and $75.9 \%$ of all cases) in colonoscopy and MRE, respectively.

We analyzed the distribution of age in location of GI involvement, which showed that patients with colon involvement had mean age of $35 \pm 13.78$ (17.77-52.22) years and patients with small bowel involvement had mean age of $39.88 \pm 14.59$ (32.37-47.38) years and those with ileocolic involvement had mean age of $32.57 \pm 12.52$ (20.98-44.15) ( $p=0.44)$.

There was a significant correlation between eye involvement and duration of disease and defecation frequency ( $p=0.044$ and 0.031 , Man Whitney test). Also we found a correlation between anemia and duration of disease $(p=0.013$, Man Whitney test).

\section{MRE vs Colonoscopy:}

We performed per segment analysis for eight critical segments (rectum, sigmoid, descending colon, ascending colon, transverse colon, cecum, ileum, and ileocecal
Table 2: Location of involvement in colonoscopy and MR enterograhy

\begin{tabular}{lccc}
\hline Colonoscopy & N & $\begin{array}{c}\text { Percent among } \\
\text { involved segments }\end{array}$ & $\begin{array}{c}\text { Percent of } \\
\text { cases }\end{array}$ \\
\hline Rectum & 7 & $8.8 \%$ & $25.9 \%$ \\
\hline Sigmoid & 10 & $12.5 \%$ & $37.0 \%$ \\
\hline Descending colon & 11 & $13.8 \%$ & $40.7 \%$ \\
\hline Transverse colon & 7 & $8.8 \%$ & $25.9 \%$ \\
\hline Ascending colon & 7 & $8.8 \%$ & $25.9 \%$ \\
\hline Cecum & 8 & $10.0 \%$ & $29.6 \%$ \\
\hline Ileocecal valve & 11 & $13.8 \%$ & $40.7 \%$ \\
\hline Ileum & & $23.8 \%$ & $70.4 \%$ \\
\hline Total & 80 & $100.0 \%$ & \\
\hline
\end{tabular}

MR Enterography

\begin{tabular}{lccc}
\hline Rectum colon & 3 & $4.7 \%$ & $10.3 \%$ \\
\hline Sigmoid colon & 7 & $10.9 \%$ & $24.1 \%$ \\
\hline Descending colon & 7 & $10.9 \%$ & $24.1 \%$ \\
\hline Transvers colon & 2 & $3.1 \%$ & $6.9 \%$ \\
\hline Ascending colon & 2 & $3.1 \%$ & $6.9 \%$ \\
\hline Cecum & 2 & $3.1 \%$ & $6.9 \%$ \\
\hline Ileum & 22 & $34.4 \%$ & $75.9 \%$ \\
\hline Ileocecal & 13 & $20.3 \%$ & $44.8 \%$ \\
\hline Jejunum & 5 & $7.8 \%$ & $17.2 \%$ \\
\hline Duodenum & 1 & $1.6 \%$ & $3.4 \%$ \\
\hline Total & 64 & $100.0 \%$ & \\
\hline
\end{tabular}

Table 3a: Colonoscopy and MR entrography findings

\begin{tabular}{lcc}
\hline Colonoscopy findings & n & Percent \\
\hline Erythema & 25 & 83.3 \\
\hline Edema & 24 & 80 \\
\hline $\begin{array}{l}\text { Vascular pattern } \\
\text { decreased }\end{array}$ & 16 & 53.3 \\
\hline Increased frability & 15 & 50 \\
\hline Aphtus ulcer & 16 & 53 \\
\hline Linear ulcer & 8 & 26.7 \\
\hline Stenosis & 6 & 20 \\
\hline Exudate & 2 & 6.7 \\
\hline Nodularity & 4 & 13.3 \\
\hline Cobble stone & 3 & 10 \\
\hline
\end{tabular}

valve) in 30 patients. We analyzed a total of 240 segments. The results of MRE (table 4) showed lesions in $58(24.17 \%)$ segments while $182(75.83 \%)$ segments were reported as negative. Of the 58 positive lesions 36 (15\%) segments were true positive and 22 (9.166\%) segments were false positive. Of the 182 negative results, $138(57.5 \%)$ and $44(18.333 \%)$ segments were true and 
Table 3b: MR entrography findings

\begin{tabular}{|c|c|c|}
\hline MR enterography findings & $\mathbf{n}$ & Percent \\
\hline Mucosal enhancement & 13 & 43.3 \\
\hline Stratification & 13 & 43.3 \\
\hline Comb sign & 9 & 30 \\
\hline Ulcer & 3 & 10 \\
\hline Mesenteric fat stranding & 5 & 16.7 \\
\hline Submucosal fat & 0 & 0 \\
\hline Mural thickening & 20 & 66.7 \\
\hline Engorged vasa recta & 8 & 26.7 \\
\hline Fibrostenosing segment & 13 & 43.3 \\
\hline Fibrofatty proliferation & 5 & 16.7 \\
\hline Dilated amorphus flaccid loops & 2 & 6.7 \\
\hline Enteroenteric fistula & 4 & 13.3 \\
\hline Mesenteric lymph node & 20 & 66.7 \\
\hline Perianal fistula & 3 & 10 \\
\hline Abscess & 4 & 13.3 \\
\hline Sacroiliitis & 0 & 0 \\
\hline Renal stone & 0 & 0 \\
\hline Gall stone & 0 & 0 \\
\hline Primary Sclerosing Cholangitis & 0 & 0 \\
\hline
\end{tabular}

false negative, respectively. Generally, sensitivity and specificity, positive likelihood ratio (PLR), negative likelihood ratio (NLR), positive predictive value (PPV), negative predictive value (NPV), and $\mathrm{K}$ of MRE in localization of lesions of the 8 segments were $45,86.25$, $3.27,0.64,62.07,75.82$, and 0.336 , respectively.

We assessed per patients involvement of CD lesions in each segment of colon, which is shown in table 5 . MRE had sensitivity and specificity of $50 \%$ and $90 \%$ with PPV and NPV of 71.43 and 78.26 for localizing sigmoid lesions, which was correlated with colonoscopic result ( $p=0.026$ and $\mathrm{K}=0.432$ ). Also its sensitivity and specificity for descending colon were 45.45 and 89.47 $(\mathrm{K}=0.378$ and $p=0.043)$.

Nevertheless the results for ileum were quite different with sensitivity and specificity of 84.21 and 45.45 and $\mathrm{K}=0.315$ and $p=0.104$.

\section{DISCUSSION}

Diagnostic accuracy of MRE in localization of CD's lesions in small bowel and colon has been determined in numerous studies. While it's accuracy for detecting small bowel lesions has been reported as $78 \%$ to $95 \%$ but there is quite controversy about application of MRE instead of colonoscopy for detecting lesions in colon. ${ }^{2,28}$ In current study we assessed the presence of ulcers, mucosal enhancement, stratification, comb sign, mesenteric fat stranding, sub mucosal fat, mural thickening, engorgement of vasa recta, fibrostenosing segment, fibrofatty proliferation, dilated amorphous flaccid loops, enteroenteric fistula, mesenteric lymph node involvement, perianal fistula, abscess, sacroileitis, renal stone, gallbladder stone, and PSC(Primary sclerosing Cholangitis) in patients with $\mathrm{CD}$ by MRE. ${ }^{7,22}$

Based on radiological imaging results, there are four subtypes of CD classifications including active inflammatory, fibrostenotic, fistulizing or perforating, and reparative or regenerative subtype. The importance of differentiating these subtypes is due to their different types of managements. Treatment of acute inflammation is via medical approaches while the required treatment

Table 4: True- and false-positive and negative findings of MRI in each segment

\begin{tabular}{lcccc}
\hline Colonic segment & True positive & False positive & True negative & False negative \\
\hline $\begin{array}{l}\text { Total number of colonic } \\
\text { segment }(\mathrm{n}=240)\end{array}$ & $36(15)$ & $22(9.166)$ & $138(57.5)$ & $44(18.333)$ \\
\hline Rectum $(\mathrm{n}=30)$ & $2(6.66)$ & $1(3.33)$ & $22(73.33)$ & $5(16.66)$ \\
\hline Sigmoid $(\mathrm{n}=30)$ & $5(16.66)$ & $2(6.66)$ & $18(60)$ & $5(16.66)$ \\
\hline Descending colon $(\mathrm{n}=30)$ & $5(16.66)$ & $2(6.66)$ & $17(56.66)$ & $6(20)$ \\
\hline Ascending colon $(\mathrm{n}=30)$ & $0(0)$ & $2(6.66)$ & $21(70)$ & $7(23.33)$ \\
\hline Transverse colon $(\mathrm{n}=30)$ & $1(3.33)$ & $1(3.33)$ & $22(73.33)$ & $6(20)$ \\
\hline Cecum $(\mathrm{n}=30)$ & $1(3.33)$ & $1(3.33)$ & $21(70)$ & $7(23.33)$ \\
\hline Ileum $(\mathrm{n}=30)$ & $16(53.33)$ & $6(20)$ & $5(16.66)$ & $3(10)$ \\
\hline Ileocecal valve $(\mathrm{n}=30)$ & $6(20)$ & $7(23.33)$ & $12(40)$ & $5(16.66)$ \\
\hline
\end{tabular}


Table 5: Sensitivity, specificity, positive likelihood ratio (PLR), negative likelihood ratio (NLR), positive predictive value (PPV), and negative predictive value (NPV) of MRI in the localization of lesions, calculated for each segment.

\begin{tabular}{|c|c|c|c|c|c|c|c|c|}
\hline Colonic segment & Sensitivity & Specificity & PLR & NLR & PPV & NPV & $\mathbf{K}$ & $P$-value \\
\hline $\begin{array}{l}\text { Total number of } \\
\text { colonic segment } \\
\quad(\mathrm{n}=240)\end{array}$ & 45 & 86.25 & 3.27 & 0.64 & 62.07 & 75.82 & 0.336 & - \\
\hline $\begin{array}{l}\text { Rectum } \\
(\mathrm{n}=30)\end{array}$ & $\begin{array}{c}28.57 \\
(4.52-70.73)\end{array}$ & $\begin{array}{c}95.65 \\
(77.98-99.27)\end{array}$ & $\begin{array}{c}6.57 \\
(0.70-62.13)\end{array}$ & $\begin{array}{c}0.75 \\
(0.46-1.20)\end{array}$ & $\begin{array}{c}66.67 \\
(11.55-94.53)\end{array}$ & $\begin{array}{c}81.48 \\
(61.90-93.63)\end{array}$ & 0.302 & 0.128 \\
\hline $\begin{array}{l}\text { Sigmoid } \\
(\mathrm{n}=30)\end{array}$ & $\begin{array}{c}50 \\
(18.89-81.11)\end{array}$ & $\begin{array}{c}90 \\
(68.26-98.47)\end{array}$ & $\begin{array}{c}5 \\
(1.17-21.39)\end{array}$ & $\begin{array}{c}0.56 \\
(0.29-1.05)\end{array}$ & $\begin{array}{c}71.43 \\
(29.27-95.48)\end{array}$ & $\begin{array}{c}78.26 \\
(56.29-92.46)\end{array}$ & 0.432 & 0.026 \\
\hline $\begin{array}{l}\text { Descending colon } \\
\quad(\mathrm{n}=30)\end{array}$ & $\begin{array}{c}45.45 \\
(16.92-76.50)\end{array}$ & $\begin{array}{c}89.47 \\
(66.82-98.39)\end{array}$ & $\begin{array}{c}4.32 \\
(1.00-18.63)\end{array}$ & $\begin{array}{c}0.61 \\
(0.35-1.07)\end{array}$ & $\begin{array}{c}71.43 \\
(29.27-95.48)\end{array}$ & $\begin{array}{c}73.91 \\
(51.59-89.71)\end{array}$ & 0.378 & 0.043 \\
\hline $\begin{array}{l}\text { Ascending colon } \\
\quad(\mathrm{n}=30)\end{array}$ & $\begin{array}{c}0 \\
(71.92-98.68)\end{array}$ & $\begin{array}{c}91.30 \\
(71.92-98.68)\end{array}$ & 0 & $\begin{array}{c}1.10 \\
(0.97-1.24)\end{array}$ & $\begin{array}{c}0 \\
(0-80.71)\end{array}$ & $\begin{array}{c}75 \\
(55.12-89.26)\end{array}$ & -0.116 & 0.582 \\
\hline $\begin{array}{l}\text { Transverse colon } \\
\quad(\mathrm{n}=30)\end{array}$ & $\begin{array}{c}14.29 \\
(2.37-57.77) \\
\end{array}$ & $\begin{array}{c}95.65 \\
(77.98-99.27) \\
\end{array}$ & $\begin{array}{c}3.29 \\
(0.23-46.02) \\
\end{array}$ & $\begin{array}{c}0.90 \\
(0.65-1.23) \\
\end{array}$ & $\begin{array}{c}50 \\
(8.17-91.83) \\
\end{array}$ & $\begin{array}{c}78.57 \\
(59.04-91.65) \\
\end{array}$ & 0.132 & 0.418 \\
\hline $\begin{array}{l}\text { Cecum } \\
(\mathrm{n}=30)\end{array}$ & $\begin{array}{c}12.50 \\
(2.07-52.62)\end{array}$ & $\begin{array}{c}95.45 \\
(77.08-99.24)\end{array}$ & $\begin{array}{c}2.75 \\
(0.19- \\
38.97)\end{array}$ & $\begin{array}{c}0.92 \\
(0.69-1.21)\end{array}$ & $\begin{array}{c}50 \\
(8.17-91.83)\end{array}$ & $\begin{array}{c}75 \\
(55.12-89.26)\end{array}$ & 0.104 & 0.469 \\
\hline $\begin{array}{l}\text { Ileocecal valve } \\
\qquad(\mathrm{n}=30)\end{array}$ & 54.55 & 63.16 & 1.48 & 0.72 & 46.15 & 70.59 & 0.171 & 0.454 \\
\hline $\begin{array}{l}\text { Ileum } \\
(\mathrm{n}=30)\end{array}$ & $\begin{array}{c}84.21 \\
(60.40-96.43)\end{array}$ & $\begin{array}{c}45.45 \\
(16.92-76.50)\end{array}$ & $\begin{array}{c}1.54 \\
(0.87-2.74)\end{array}$ & $\begin{array}{c}0.35 \\
(0.10-1.18)\end{array}$ & $\begin{array}{c}72.73 \\
(49.78-89.20)\end{array}$ & $\begin{array}{c}62.50 \\
(24.70-91.03)\end{array}$ & 0.315 & 0.104 \\
\hline
\end{tabular}

for fibrostenotic disease is surgery. ${ }^{29,30}$ There are various structural and functional factors for assessing active disease in MRE. These factors include wall thickening, higher degree and pattern of enhancement, intensity of T2 mural signal, local lymph node enhancement, higher mesenteric vascularity that are known to be correlated with laboratory data, endoscopic results or histological activity of CD. ${ }^{30}$ Wall thickness degree (more than $3 \mathrm{~mm}$ ) is known to be correlated with Crohn's Disease Activity Index and inflammation degree in histopathology. ${ }^{29,30}$ Active inflammation has higher degree of mural thickening in contrast to chronic inflammation or fibrostenotic disease. ${ }^{29,31}$ Mural stratification also confirms active Crohn's disease. Stratified type of bowel enhancement is referred to increase in mucosal enhancement with submucosal edema, which suggests acute disease. However non-stratified complete thickness enhancement of bowel wall can also suggest acute inflammation. Fibrostenotic disease is characterized by less keen wall enhancement. $^{29}$ Some patients with progressive active disease show evidence of mesenteric edema. Other signs of acute inflammation are signal hypersensitivity of intestinal wall in T2 images demonstrating wall edema and increase in intravenous (IV) contrast enhancement in the bowel wall that are correlated with biological parameters and histological findings. ${ }^{29,30}$ Some studies have suggested the increase in mucosal enhancement or a stratified pattern of bowel wall enhancement in active inflammation as a result of existence of submucosal edema. Some other studies have also proposed heterogeneous, homogeneous, and stratified pattern of enhancement in chronic or fibrostenotic disease. The hypothesis for solving this inconsistency was occurrence of an active disease on a chronic fibrostenotic disease resulting in stratified pattern of enhancement. ${ }^{29,31}$ So radiologists should recommend clinicians that this narrowing might be reversible if it is just because of edema or spasm caused by active disease or become fixed if it is caused by fibrosis that can be seen in chronic phase. Because treatment of active or chronic phases are totally different, differentiating these two conditions are vital. ${ }^{31}$ In a study by Koh and colleagues 13 active disease was defined by abnormal mural thickness $(>3 \mathrm{~mm})$, increased mural enhancement with or without perienteric changes, presence of fistula or abscess. Lately MRIA (magnetic resonance index of activity), which consists of a formula including mural thickness, edema, ulceration, and mural contrast enhancement for each segment of intestine, is used for assessing dis- 
ease severity quantitatively based on MRE. ${ }^{32}$ Active CD on CT images are also characterized by mural thickening, hyper enhancement and stratification, enlarged vasa recta (comb sign), and higher density of peri enteric fat while fibrotic strictures and submucosal fat depositions are some of the characteristics of chronic disease. ${ }^{31} \mathrm{Gen}$ erally the principal advantage of MRE over other imaging techniques is its capability in assessing signs of CD that are beyond the reach of traditional endoscopes including transmural or extraluminal involvement. ${ }^{2,7}$ Patel and colleagues $^{2}$ reported $23.2 \%$ penetrating complications consisting $18.3 \%$ and $4.8 \%$ fistula and abscess, respectively. The rate of enteroentric fistula, perianal fistula, and abscess detected by MRE in our study were $13.3 \%, 10 \%$, and $13.3 \%$, respectively.

The primary purpose of our study was to determine the diagnostic accuracy of MRE in localizing CD lesions in colon rather than small bowel in Iranian population. Overall, our study demonstrated a sensitivity of $45 \%$ and a specificity of $86.25 \%$ with PPV and NPV of 62.07 , and 75.82, respectively for MRE in detecting CD lesions in eight critical segments with fair agreement with colonoscopy $(K=0.336)$. This result was quite different from the report by Maccioni and colleagues..$^{28}$ They reported a sensitivity and specificity of $94.5 \%$, and $97 \%$ with PPV and NPV of $94.5 \%$, and $97 \%$, respectively $(K=0.93)$. Grand and co-workers33 reported sensitivity and specificity of $85 \%$ and $80 \%$, respectively $(K=0.65)$ for MRE compared with endoscopic evaluation among 310 patients with CD. In a review by Patel and colleagues ${ }^{2}$ the agreement between MRE and endoscopy in localizing active $\mathrm{CD}$ in ileum was $\mathrm{K}=0.36$. They described that the reason for different results of studies could be the variation in time intervals between MRE and endoscopy that led to possible changes of disease activity because of treatment courses, as a result, different accuracy in studies. We prevented this error by reducing the interval between colonoscopy and MRE. The two procedures were performed on the same day or maximum within a 2-week interval that yielded into similar agreement $(K=0.336)$ between the procedures. In per segment analysis, the accuracy of MRE was only significant in detecting sigmoid and descending colon lesions that was correlated with colonoscopy ( $p=0.026$ and 0.043 , respectively) with sensitivity and specificity of $(50 \%, 90 \%$, and 45.45 , 89.47 ) for sigmoid and descending colon respectively. Generally, MRE had moderate sensitivity (89.47\%) and high specificity $(95.65 \%)$ for detecting colonic lesions consequently it is not suitable as a screening test and is more appropriate to be used as a confirmatory test after colonoscopy. These are usually the gold standard tests. They may be expensive or invasive so you do not want to do them on everyone, but they are important for a final answer. Maccioni and colleagues ${ }^{28}$ reported sensitivity and specificity of $96 \%$ and $90 \%$ (for sigmoid lesions), $100 \%$ and $92 \%$ (for descending colon lesions), respectively $(K=0.91)$. The result of analysis for ileum was quite different with sensitivity and specificity of $84.21 \%$ and $45.45 \%$, respectively $(K=0.315)$ showing a fair agreement with colonoscopy. This result indicates the fact that MRE is a highly sensitive test with moderate specificity compared with colonoscopy. A negative result in a highly specific test rules out the disease. It is a good test for screening to pick up every one with the possibility of having the disease. However we can identify some of them who do not actually have the disease by other tests that have higher specificity. This is because we do not want to miss anybody in this screening test. Maccioni and co-workers ${ }^{28}$ reported high sensitivity and specificity of $100 \%$ for MRE for evaluating distal ileum. Other studies have shown sensitivity of $89 \%$ and $83 \%$, and specificity of $80 \%$ and $100 \%$, respectively for CTE (Computed tumographic Enterology) and MRE in detecting active inflammation. MRE also has higher accuracy $(100 \%)$ for detecting extraenteric complications. Nevertheless MRI in contrast to CT is superior in detection of fistulas and strictures. ${ }^{31}$ Siddiki and colleagues ${ }^{21}$ showed sensitivity and specificity of $95.2 \%$ and $90.5 \%$, respectively for MRE in detecting active $\mathrm{CD}$ of small bowel.

Several studies have concentrated on adequate bowel filling and bowel distention as an important factor for achieving good images. Some studies have demonstrated that even by using less or no amount of oral contrast good results can be achieved and also patients who are acutely ill cannot endure large volumes of oral or rectal contrasts. In addition regardless of using large oral volumes of contrast, distension of distal small bowel can be poor. ${ }^{13}$ In our study, adequate luminal distension was determined 
by a control T2 HASTE image in coronal section. If satisfactory luminal distention was achieved then MRE images were taken otherwise if adequate luminal distention was not achieved, control images were repeated every 5 minutes until achieving acceptable luminal distension, then MRE images were taken. Presence of air or fecal content in colon may also result in poor images. Air in colon can cause considerable vulnerability to artifacts and fecal content of colon may have high signals. These factors can cause reduction in observing colonic wall after using IV contrast. Studies have suggested administering water or rectal saline before MRE to improve detecting colonic lesions. ${ }^{13}$ Patients preparation before MRE in our study consisted of 4-6 hours of fasting. And an hour prior to imaging, 3 liters of PEG solution ( $75 \mathrm{gr} / \mathrm{L})$ as an oral contrast media was administered to all cases every 5 minutes to achieve the small bowel distention. In order to attenuate the bowel peristalsis and achieve a homogenous bowel distention, $20 \mathrm{mg}$ Hyoscine-N-butylbromide (Osveh, Tehran, IRAN) was administered intramuscularly to each patient prior to MRE and IV injection during MRE. Axial and coronal images of T2w were taken first and T1 images were obtained after injection of $15 \mathrm{~mL}$ of Dotarem (GadoterateMeglumine, importer company coildaroo, originally produced by GUERBET company, FRANCE) containing gadolinium. We did not use rectal saline before MRE that can be one of the limitations of our study leading to more false negative results.

To draw a conclusion, our study demonstrated moderate sensitivity and high specificity for MRE in localizing colonic lesions so it is better to be used as a confirmatory test after colonoscopy. However, the results for detecting ileal lesions indicate high sensitivity test with moderate specificity for MRE versus colonoscopy thus it can be a good screening test to evaluate the suspected individuals and confirm the results with higher specificity tests. Since the possibility of ileal involvement is the highest during the first years of diagnosis therefore MRE can be a good screening test to rule out the disease. Finally we can conclude that MRE can be an important complementary test to colonoscopy in detecting active disease.

\section{ACKNOWLEDGEMENT}

We thank Tehran University of Medical Sciences for financial support of our study.

\section{CONFLICT OF INTEREST}

The authors declare no conflict of interest related tothis work.

\section{REFERENCES}

1. Yacoub JH, Obara P, Oto A. Evolving role of MRI in Crohn's disease. J Magn Reson Imaging 2013;37:127789. doi:10.1002/jmri.24081.

2. Patel NS, Pola S, Muralimohan R, Zou G, Santillan C, Patel D, et al. Outcomes of Computed Tomography and Magnetic Resonance Enterography in Clinical Practice of Inflammatory Bowel Disease. Dig Dis Sci 2014;59:83849. doi: 10.1007/s10620-013-2964-7.

3. Fiorino G, Bonifacio C, Peyrin-Biroulet L, Minuti F, Repici A, Spinelli A, et al. Prospective comparison of computed tomography enterography and magnetic resonance enterography for assessment of disease activity and complications in ileocolonic Crohn's disease. Inflamm Bowel Dis 2011;17:1073-80. doi: 10.1002/ibd.21533.

4. Baumgart DC, Sandborn WJ. Crohn's disease. Lancet 2012;380:1590-605. doi: 10.1016/S0140-6736(12)60026-9.

5. Peyrin-Biroulet L, Loftus EV, Colombel JF, Sandborn WJ. The natural history of adult Crohn's disease in populationbased cohorts. Am J Gastroenterol 2010;105:289-97. doi: 10.1038/ajg.2009.579.

6. Martin DR, Lauenstein T, Sitaraman SV. Utility of magnetic resonance imaging in small bowel Crohn's disease. Gastroenterology 2007;133:385-90. doi:10.1053/j.gastro. 2007.06.036

7. Sajjadi M, Gholamrezaei A, Daryani NE. No Association Between Serum Adenosine Deaminase Activity and Disease Activity in Crohn's Disease. Dig Dis Sci 2015;60:1755-60. doi: 10.1007/s10620-014-3510-y.

8. Anbardan SJ, Azizi Z, Daryani NE, Motamedi M. Peripheral Neuropathy in Ulcerative Colitis: A Case Report. Govaresh 2015;20:66-9.

9. Louis E. Epidemiology of the transition from early to late Crohn's disease. Dig Dis 2012;30:376-9. doi: $10.1159 / 000338129$.

10. Loftus E, Schoenfeld P, Sandborn W. The epidemiology and natural history of Crohn's disease in populationbased patient cohorts from North America: a systematic review. Aliment Pharmacol Ther 2002;16:51-60. doi: 10.1046/j.1365-2036.2002.01140.x

11. Freeman HJ. Natural history and clinical behavior of Crohn's disease extending beyond two decades. J Clin Gastroenterol 2003;37:216-9.

12. Rimola J, Rodríguez S, García-Bosch O, Ordás I, Ayala E, Aceituno M, et al. Magnetic resonance for assessment of disease activity and severity in ileocolonic Crohn's disease. Gut 2009;58:1113-20. doi:10.1136/gut.2008.167957

13. Koh D, Miao Y, Chinn R, Amin Z, Zeegen R, Westaby D, et al. MR imaging evaluation of the activity of Crohn's 
disease. AJR Am J Roentgenol 2001;177:1325-32.

14. Van Assche G, Dignass A, Panes J, Beaugerie L, Karagiannis J, Allez M, et al. The second European evidencebased consensus on the diagnosis and management of Crohn's disease: definitions and diagnosis. $J$ Crohns Colitis 2010;4:7-27. doi: 10.1016/j.crohns.2009.12.003.

15. Lee SS, Kim AY, Yang SK, Chung JW, Kim SY, Park SH, et al. Crohn Disease of the Small Bowel: Comparison of CT Enterography, MR Enterography, and Small-Bowel Follow-Through as Diagnostic Techniques 1. Radiology 2009;251:751-61. doi: 10.1148/radiol.2513081184.

16. Travis S, Stange E, Lémann M, Öresland T, Chowers Y, Forbes A, et al. European evidence based consensus on the diagnosis and management of Crohn's disease: current management. Gut 2006;55(suppl 1):i16-i35. doi:10.1136/ gut.2005.081950b

17. Albert JG, Martiny F, Krummenerl A, Stock K, Lesske J, Göbel CM, et al. Diagnosis of small bowel Crohn's disease: a prospective comparison of capsule endoscopy with magnetic resonance imaging and fluoroscopic enteroclysis. Gut 2005;54:1721-7. doi:10.1136/gut.2005.069427

18. Saibeni S, Rondonotti E, Iozzelli A, Spina L, Tontini GE, Cavallaro F, et al. Imaging of the small bowel in Crohn's disease: a review of old and new techniques. World J Gastroenterol 2007;13:3279-87.

19. Grand DJ, Harris A, Loftus EV. Imaging for luminal disease and complications: CT enterography, MR enterography, small-bowel follow-through, and ultrasound. Gastroenterol Clin North Am 2012;41:497-512. doi:10.1016/j. gtc.2012.01.015.

20. Sinha R, Verma R, Verma S, Rajesh A. MR enterography of Crohn disease: part 1, rationale, technique, and pitfalls. AJR Am J Roentgenol 2011;197:76-9. doi: 10.2214/ AJR.10.7253.

21. Siddiki H, Fidler J. MR imaging of the small bowel in Crohn's disease. Eur J Radiol 2009;69:409-17. doi: 10.1016/j.ejrad.2008.11.013.

22. Jensen MD, Kjeldsen J, Rafaelsen SR, Nathan T. Diagnostic accuracies of MR enterography and CT enterography in symptomatic Crohn's disease. Scand J Gastroenterol 2011;46:1449-57. doi:10.3109/00365521.2011.613947.

23. Desmond AN, O'Regan K, Curran C, McWilliams S, Fitzgerald T, Maher MM, et al. Crohn's disease: factors associated with exposure to high levels of diagnostic radiation. Gut 2008;57:1524-9. doi:10.1136/gut.2008.151415

24. Cipriano LE, Levesque BG, Zaric GS, Loftus EV, Sandborn WJ. Cost-effectiveness of imaging strategies to reduce radiation-induced cancer risk in Crohn's disease. Inflamm Bowel Dis 2012;18:1240-8. doi: 10.1002/ ibd. 21862 .

25. Bernstein CN, Greenberg H, Boult I, Chubey S, Leblanc C, Ryner L. A prospective comparison study of MRI versus small bowel follow-through in recurrent Crohn's disease. Am J Gastroenterol 2005;100:2493-502. doi:10.1111/j. 1572-0241.2005.00239.x
26. Laghi A, Borrelli O, Paolantonio P, Dito L, de Mesquita MB, Falconieri $\mathrm{P}$, et al. Contrast enhanced magnetic resonance imaging of the terminal ileum in children with Crohn's disease. Gut 2003;52:393-7. doi:10.1136 gut.52.3.393

27. Fujii T, Naganuma M, Kitazume Y, Saito E, Nagahori M, Ohtsuka K, et al. Advancing magnetic resonance imaging in Crohn's disease. Digestion 2014;89:24-30. doi:10. $1159 / 000356210$

28. Maccioni F, Ansari NA, Mazzamurro F, Civitelli F, Viola F, Cucchiara S, et al. Detection of Crohn Disease Lesions of the Small and Large Bowel in Pediatric Patients: Diagnostic Value of MR Enterography Versus Reference Examinations. AJR Am J Roentgenol 2014;203:W533-42. doi: 10.2214/AJR.13.11792.

29. Griffin N, Grant LA, Anderson S, Irving P, Sanderson J. Small bowel MR enterography: problem solving in Crohn's disease. Insights Imaging 2012;3:251-63. doi: 10.1007/s13244-012-0154-3.

30. Yoon K, Chang KT, Lee HJ. MRI for Crohn's Disease: Present and Future. Biomed Res Int 2015;2015:786802. doi:10.1155/2015/786802.

31. Kim SH. Computed Tomography Enterography and Magnetic Resonance Enterography in the Diagnosis of Crohn's Disease. Intest Res 2015;13:27-38. doi: 10.5217/ ir.2015.13.1.27.

32. Amitai MM, Ben-Horin S, Eliakim R, Kopylov U. Magnetic resonance enterography in Crohn's disease: A guide to common imaging manifestations for the IBD physician. J Crohns Colitis 2013;7:603-15. doi:10.1016/j.crohns. 2012.10.005.

33. Grand DJ, Kampalath V, Harris A, Patel A, Resnick MB, Machan J, et al. MR enterography correlates highly with colonoscopy and histology for both distal ileal and colonic Crohn's disease in 310 patients. Eur J Radiol 2012;81:e763-9. doi: 10.1016/j.ejrad.2012.02.011. 